\title{
Similarities and Differences in the European Entrepreneurial Activities
}

\author{
Barrachina, Mercedes
}

\section{San Pablo CEU University, Law and Economics Program, CEINDO, Spain. Email:mar.barrachina.ce@.ceindo.ceu.es \\ Licensed: \\ This work is licensed under a Creative Commons Attribution 4.0 License.}

Keywords:

Entrepreneurship

Differences

European characteristics

Entrepreneurial activities.

JEL Classification

F41; L26.

Received: 8 September 2021

Revised: 30 September 2021

Accepted: 15 October 2021

Published: 2 November 2021

\begin{abstract}
Entrepreneurship is a key activity in the economy as it influences in the economic performance by creating new products, new solutions, new methods, new processes and new jobs. High levels entrepreneurship in economies have a positive impact on productivity and competitiveness. According to data from Eurostat (2018), in 2018 in Europe, 3.3 million jobs were created thanks to the 2.5 million companies that were created. Moreover, in 2018, there were a total of 25.3 million active enterprises employing a total of 131 million people. Some of the most relevant entrepreneurial hotpots in Europe are Estonia, Sweden, Latvia and the Netherlands (World Economic Forum, 2017). The main objective of this work is to identify and compare the different European geographical areas and evaluate the characteristics and variables that promote entrepreneurship from the experts' point of view. The GEM database was utilized to extract data for analysis in this research. The results obtained show differences between the Northern and Southern countries for the two analysis perspectives used.
\end{abstract}

Funding: This study received no specific financial support.

Competing Interests: The author declares that there are no conflicts of interests regarding the publication of this paper.

\section{Introduction}

The last few years have been important in helping us to understand the theoretical and practical reasons behind the explosion in the creation of startups in different environments. There has been a growing interest in understanding personal circumstances, educational background, personal skills, and management attitudes related to the decision to become an entrepreneur. In relation to innovative businesses, in the last decade there have been a large number of academics who have focused on identifying the characteristics of the most innovative businesses and their founders.

In the existing literature, there are studies related to the analysis of the temporal and geographical factors that influence entrepreneurial activities (Beynon, Jones, \& Pickernell, 2016; Khyareh \& Torabi, 2018). Specifically in emerging economies and in developing countries the research on entrepreneurship has attracted growing interest. For example, Klimis (2019) evaluated the most relevant factors affecting business attitudes, intentions, perceptions and aspirations in developing economies.

The evaluation of different innovative startups in several OECD countries (Breschi, Lassébie, \& Menon, 2018) showed that there are significant differences between countries in the education of startups. It has also been stated that the political priority in all OECD countries aims to create the right conditions for innovative companies to grow and prosper.

There are several differences in the entrepreneurship environments in different regions. For example, according to Lopes, Rodrigues, \& Antunes (2018), there are significant differences between the characteristics of entrepreneurship in Western Europe and those in Latin America. In general, the different geographical, historical, cultural and economic factors that affect different countries influence the business activities of a region in different ways.

Historically, Northern European countries have had greater economic, institutional, and regulatory development, so it is interesting to analyze how this polarization affects the level of business conditions and the level of attitudes among entrepreneurs. Polarization in entrepreneurship is not a highly researched topic in literature and, therefore, this study aims to investigate this area. 
The main goal of this study is to carry out empirical research to evaluate the differences between the North and the South of Europe in terms of business context and skills to become an entrepreneur. Overall, the chapter has been organized as follows: Section 2 explains the research methodology and data collection; Section 3 details the results; Section 4 contains the discussion; and Section 5 comprises the conclusions, as well as limitations and future lines of research.

\section{Method}

Data from the GEM database for 2015 (latest year available with data at the national level when performing this analysis) were used, which contains information from 62 different countries. This study is focused on analyzing the differences between Northern Europe (North) and Southern Europe (South), so the information is filtered by the countries within the scope of the study.

The analysis is based on two different approaches. First, the information regarding the general context of the country is introduced (business conditions) and assessed by experts (NES survey). Second, for the attitudes and skills approach, information regarding the skills of the entrepreneurs is utilized at national level and valued by entrepreneurs (APS surveys).

Table 1 details the countries in the scope of this research for both the Northern and Southern zones.

\begin{tabular}{l|l}
\multicolumn{2}{c}{ Table 1. Countries in scope. } \\
\hline Area & Countries \\
\hline Northern area & Croatia, Slovenia, Spain, Greece, Italy, Portugal \\
\hline Southern area & Estonia, Finland, Ireland, Latvia, Norway, United Kingdom, Sweden \\
\hline
\end{tabular}

\subsection{Business Conditions Overview}

The Northern Europe group consists of six countries, and the Southern Europe group consists of seven countries. The variables used in this work have been extracted from the GEM database at the expert level (NES) and the national level, and the variable TEA (total entrepreneurship activity) has been added from the same database (APS).

The variables used in this study are detailed below in Table 2 and Table 3:

Table 2. Variables for business conditions.

\begin{tabular}{l|l}
\hline Variable & Description \\
\hline NES15_A (A) & Financial environment related to entrepreneurship (\%) \\
\hline NES15_B1 (B1) & Specific government policies, priority and support (\%) \\
\hline NES15_B2 (B2) & Government policies, bureaucracy and taxes (\%) \\
\hline NES15_C(C) & Government programs (\%) \\
\hline NES15_D1 (D1) & Level of training in entrepreneurship in primary and secondary schools (\%) \\
\hline NES15_D2 (D2) & Level of training in entrepreneurship in university and professional education (\%) \\
\hline NES15_E ( E ) & R\&D transfer level (\%) \\
\hline NES15_F(F) & Access to professional and commercial infrastructure (\%) \\
\hline NES15_G1 (G1) & Internal market dynamics (\%) \\
\hline NES15_G2 (G2) & Internal market barriers (\%) \\
\hline NES15_H(H) & Access to physical infrastructure and services (\%) \\
\hline NES15_I (I) & Social and cultural support (\%) \\
\hline NES15_S1 (S1) & Companies providing basic social needs (\%) \\
\hline NES15_S2 (S2) & Consumer, government and media support for social entrepreneurship (\%) \\
\hline
\end{tabular}

Table 3. Variables for the attitudes and skills perspective.

\begin{tabular}{l|l}
\hline Variable & Description \\
\hline Busang 15 & The interviewee got involved in entrepreneurship activities as an informal investor \\
\hline Knoent 15 & The interviewee knows someone personally who started a business in the last two years \\
\hline Opport15 & The interviewee recognized a good opportunity to start a business in the area where they live \\
\hline Suskil15 & The interviewee was perceived to have the knowledge and skills necessary to start a business \\
\hline Frfail15 & Fear of failure prevented the interviewee from starting a business \\
\hline nbgoodc & The interviewee considered starting a business as a desirable career \\
\hline nbstatus & $\begin{array}{l}\text { The interviewee considers that those who are successful in starting a business have a high } \\
\text { levels of status and respect }\end{array}$ \\
\hline Amount & Total money needed to start the business (national average) \\
\hline
\end{tabular}




\subsection{Attitudes and Skills Perspective}

The total entrepreneurship activity (TEA) variable is presented in percentage format and includes adults (between 18 and 64 years old) who are actively starting a new business or are owners of a company that started its operations in the last 42 months.

The Kolmogorov-Smirnov test, Mann-Whitney test and the Student's t-test were used to validate the hypotheses raised depending on the distributions that each of the variables follow.

\section{Results}

The results are shown in two different sections, one corresponding to business conditions and one related to the attitudes and skills perspective.

\subsection{Business Conditions}

The analysis started by performing a normality test on the data to be analyzed. First, to assess whether the data follow a normal distribution, the Kolmogorov-Smirnov normality test was used. The hypothesis proposed for this analysis is detailed below: Ho - The analyzed variable follows a normal distribution.

Table 4. Kolmogorov-Smirnov test results for business conditions.

\begin{tabular}{c|c|c}
\hline Variable & Statistic & Sig. \\
\hline NES15_A & 0.145 & 0.200d \\
\hline NES15_B1 & 0.167 & $0.200 d$ \\
\hline NES15_B2 & 0.155 & $0.200 d$ \\
\hline NES15_C & 0.267 & 0.012 \\
\hline NES15_D1 & 0.184 & $0.200 d$ \\
\hline NES15_D2 & 0.162 & 0.200d \\
\hline NES15_E & 0.173 & $0.200 d$ \\
\hline NES15_F & 0.168 & $0.200 d$ \\
\hline NES15_G1 & 0.17 & $0.200 d$ \\
\hline NES15_G2 & 0.168 & $0.200 d$ \\
\hline NES15_H & 0.17 & $0.200 d$ \\
\hline NES15_I & 0.159 & $0.200 d$ \\
\hline NES15_S1 & 0.151 & $0.200 d$ \\
\hline NES15_S2 & 0.154 & $0.200 d$ \\
\hline TEA & 0.228 & 0.062 \\
\hline
\end{tabular}

According to the results shown in Table 4, the variable NES15_C (C) rejects hypothesis Ho; therefore, a different distribution to the normal distribution is followed. The rest of the variables accept the null hypothesis and they follow a normal distribution, so are therefore considered valid. Based on these results, the Mann-Whitney test is applied to the variable that does not follow a normal distribution (with the main objective of identifying differences between two populations), while the Student's t-test and analysis of variance (ANOVA) are applied to the variables that follow a normal distribution.

For the variable for which the null hypothesis has been rejected, i.e., NES15_C (C), the Mann-Whitney test is performed to identify the differences in the central tendency of the two independent groups (the null hypothesis is taken as the median if the two groups are equal).

Table 5. Results of the Mann-Whitney test in the analysis of business conditions.

\begin{tabular}{c|c|c|c|c}
\hline Variable & Group & N & Average range & Sum of ranks \\
\hline \multirow{2}{*}{ NES15_C } & 1 & 6 & 5.33 & 32.00 \\
\cline { 2 - 5 } & 2 & 7 & 8.43 & 59.00 \\
\hline
\end{tabular}

The results shown in Table 5 show that the analyzed variable, which corresponds to government policies and taxes, has a higher average rank in the Northern countries than in the Southern countries. Analyzing the values of the Mann-Whitney test (as shown in Table 6), it is concluded that the null hypothesis can be accepted and, therefore, the two groups have a similar central tendency.

Table 6. Statistical results of the Mann-Whitney test in the analysis of business conditions.

\begin{tabular}{c|c}
\hline Test statistics & NES15_C \\
\hline Mann-Whitney U & 11.000 \\
\hline Wilcoxon W & 32.000 \\
\hline Z & -1.429 \\
\hline Asymp. Sig. (2-tailed) & 0.153 \\
\hline Exact Sig. & $0.181 \mathrm{~b}$ \\
\hline
\end{tabular}


Next, the Student's t-test is applied to the variables that accepted the Ho hypothesis in the normality test. In this test, the variables NES15_A, NES15_B, NES15_D1, NES15_D2, NES15_E, NES15_F, NES15_G1, NES15_G2, NES15_H, NES15_I, NES15_S1, NES15_S2 and TEA are analyzed.

Table 7. Statistical results of the Student's t-test in the analysis of business conditions.

\begin{tabular}{|c|c|c|c|c|c|}
\hline \multicolumn{6}{|c|}{ Group Statistics } \\
\hline \multicolumn{2}{|l|}{ Group } & $\mathbf{N}$ & Mean & Std. Deviation & Std. Error Mean \\
\hline \multirow[t]{2}{*}{ NES15_A } & 1 & 6 & 3.86547302917 & 0.608018799016 & 0.248222635268 \\
\hline & 2 & 7 & 4.75274449157 & 0.487723786433 & 0.184342263913 \\
\hline \multirow[t]{2}{*}{ NES15_B1 } & 1 & 6 & 3.64638040200 & 0.832862487608 & 0.340014686757 \\
\hline & 2 & 7 & 4.29353704629 & 0.665438985373 & 0.251512295426 \\
\hline \multirow[t]{2}{*}{$\mathrm{NES} 15 \_\mathrm{B} 2$} & 1 & 6 & 3.22283398233 & 1.415552605495 & 0.577896931255 \\
\hline & 2 & 7 & 4.41725102257 & 0.469893599024 & 0.177603086526 \\
\hline \multirow[t]{2}{*}{ NES15_D1 } & 1 & 6 & 3.23954219367 & 1.268978214322 & 0.518058186633 \\
\hline & 2 & 7 & 3.92150381757 & 0.199484337201 & 0.075397992384 \\
\hline \multirow[t]{2}{*}{ NES15_D2 } & 1 & 6 & 4.20098152267 & 0.435525918413 & 0.177802711645 \\
\hline & 2 & 7 & 4.62837872886 & 0.545510997585 & 0.206183776723 \\
\hline \multirow[t]{2}{*}{ NES15_E } & 1 & 6 & 3.92866478850 & 0.774776001392 & 0.316300978061 \\
\hline & 2 & 7 & 4.13686045300 & 0.384223276596 & 0.145222748256 \\
\hline \multirow[t]{2}{*}{ NES15_F } & 1 & 6 & 4.46480757583 & 0.159165985786 & 0.064979241597 \\
\hline & 2 & 7 & 5.50725108971 & 0.460232391046 & 0.173951493143 \\
\hline \multirow[t]{2}{*}{ NES15_G1 } & 1 & 6 & 5.08584364600 & 0.677937018562 & 0.276766628870 \\
\hline & 2 & 7 & 5.01840227329 & 0.584363447128 & 0.220868622340 \\
\hline \multirow[t]{2}{*}{ NES15_G2 } & 1 & 6 & 3.90610713783 & 0.749665323576 & 0.306049586770 \\
\hline & 2 & 7 & 4.68234299386 & 0.338314527226 & 0.127870871994 \\
\hline \multirow[t]{2}{*}{ NES15_H } & 1 & 6 & 5.44360753367 & 1.125028133943 & 0.459290812406 \\
\hline & 2 & 7 & 6.96381634243 & 0.607669206481 & 0.229677371391 \\
\hline \multirow[t]{2}{*}{ NES15_I } & 1 & 6 & 3.78843565217 & 0.902088832637 & 0.368276223771 \\
\hline & 2 & 7 & 5.05595770900 & 0.449854473528 & 0.170029009018 \\
\hline \multirow[t]{2}{*}{ NES15_S1 } & 1 & 6 & 4.60013272250 & 0.248465760827 & 0.101435722096 \\
\hline & 2 & 7 & 4.41936967543 & 0.530133836503 & 0.200371756138 \\
\hline \multirow[t]{2}{*}{$\mathrm{NES} 15 \_\mathrm{S} 2$} & 1 & 6 & 3.98328869750 & 0.626469149955 & 0.255754959497 \\
\hline & 2 & 7 & 5.00841822400 & 0.378501768710 & 0.143060221544 \\
\hline \multirow[t]{2}{*}{ TEA } & 1 & 6 & 6.733819279855 & 1.657850010559 & 0.676814432656 \\
\hline & 2 & 7 & 8.987592508418 & 3.365243386328 & 1.271942443061 \\
\hline
\end{tabular}

The statistical results obtained from the means of each of the variables for the analyzed groups show that all variables have higher values for the Northern group than for the Southern group, except for $G 1$ and $S 1$ (variables representing the internal market dynamics and the companies providing basic and social needs, respectively).

The variables $B 1, B 2, D 2, E, G 1$ and $T E A$ show no significant differences in terms of variance and also show no significant differences in the values between the Northern and Southern countries. These variables correspond to specific government policies for priority and support $(B 1)$, the government policies for bureaucracy and taxes $(B 2)$, the level of training in entrepreneurship in universities and professional education (D2), R\&D transfer level $(E)$, internal market dynamics $(G 1)$, and the level of entrepreneurship (TEA).

Analysis of the variables $D 1$ and $S 1$ shows that there are significant differences in terms of the variance of the two groups; however, there are no significant differences between the mean values of those variables between the Northern and Southern countries.

On the other hand, for the variables $A, G 2, H, I, S 2$, no significant differences were found regarding the variance; however, the null hypothesis is rejected as the p-value is $<0.05$, which indicates that there are significant differences between the mean values of these variables between the countries in the North and the countries in the South. From Table 7 it can be seen that the means of these variables are higher in the Northern countries with respect to Southern countries.

Finally, analysis of the values for the variable $F$ (see Table 8) shows that there are significant differences in terms of the variance of the two groups, and there are also significant differences between the mean values of this variable between the Northern and Southern countries.

In conclusion, for variables $A, F, G 2, H, I$ and $S 2$, differences between the means of the Northern group and the Southern group are determined, identifying that the average level for all variables is higher in the countries of Northern Europe with respect to the Southern Europe group. These variables correspond to the financial environment $(A)$, access to professional and commercial infrastructure $(F)$, internal market barriers 
$(G 2)$, physical infrastructure $(H)$, cultural and societal support for entrepreneurship $(I)$, and demand for social responsibility of entrepreneurs by social agents $(S 2)$.

Table 8. Student's t-test results for the business conditions variables

\begin{tabular}{|c|c|c|c|c|c|c|}
\hline & & \multicolumn{2}{|c|}{$\begin{array}{c}\text { Levene's Test for } \\
\text { Equality of Variances }\end{array}$} & \multicolumn{3}{|c|}{ T-test for Equality of Means } \\
\hline & & $\mathbf{F}$ & Sig. & $t$ & df & Sig. (2-tailed) \\
\hline \multirow[t]{2}{*}{ NES15_A } & Equal variances assumed & 0.219 & 0.649 & -2.923 & 11 & 0.014 \\
\hline & Equal variances not assumed & & & -2.870 & 9.602 & 0.017 \\
\hline \multirow[t]{2}{*}{ NES15_B1 } & Equal variances assumed & 0.543 & 0.477 & -1.559 & 11 & 0.147 \\
\hline & Equal variances not assumed & & & -1.530 & 9.579 & 0.158 \\
\hline \multirow[t]{2}{*}{ NES15_B2 } & Equal variances assumed & 3.923 & 0.073 & -2.114 & 11 & 0.058 \\
\hline & Equal variances not assumed & & & -1.976 & 5.945 & 0.096 \\
\hline \multirow[t]{2}{*}{ NES15_D1 } & Equal variances assumed & 5.175 & 0.044 & -1.412 & 11 & 0.186 \\
\hline & Equal variances not assumed & & & -1.303 & 5.212 & 0.247 \\
\hline \multirow[t]{2}{*}{ NES15_D2 } & Equal variances assumed & 1.133 & 0.310 & -1.541 & 11 & 0.152 \\
\hline & Equal variances not assumed & & & -1.570 & 10.965 & 0.145 \\
\hline \multirow[t]{2}{*}{ NES15_E } & Equal variances assumed & 0.429 & 0.526 & -0.630 & 11 & 0.542 \\
\hline & Equal variances not assumed & & & -0.598 & 7.068 & 0.568 \\
\hline \multirow[t]{2}{*}{ NES15_F } & Equal variances assumed & 7.002 & 0.023 & -5.257 & 11 & 0.000 \\
\hline & Equal variances not assumed & & & -5.614 & 7.613 & 0.001 \\
\hline \multirow[t]{2}{*}{ NES15_G1 } & Equal variances assumed & 0.356 & 0.563 & 0.193 & 11 & 0.851 \\
\hline & Equal variances not assumed & & & 0.190 & 10.012 & 0.853 \\
\hline \multirow[t]{2}{*}{ NES15_G2 } & Equal variances assumed & 3.370 & 0.094 & -2.475 & 11 & 0.031 \\
\hline & Equal variances not assumed & & & -2.340 & 6.727 & 0.053 \\
\hline \multirow[t]{2}{*}{ NES15_H } & Equal variances assumed & 2.400 & 0.150 & -3.100 & 11 & 0.010 \\
\hline & Equal variances not assumed & & & -2.960 & 7.426 & 0.020 \\
\hline \multirow[t]{2}{*}{ NES15_I } & Equal variances assumed & 2.242 & 0.162 & -3.287 & 11 & 0.007 \\
\hline & Equal variances not assumed & & & -3.125 & 7.090 & 0.016 \\
\hline \multirow[t]{2}{*}{ NES15_S1 } & Equal variances assumed & 5.241 & 0.043 & 0.763 & 11 & 0.462 \\
\hline & Equal variances not assumed & & & 0.805 & 8.778 & 0.442 \\
\hline \multirow[t]{2}{*}{ NES15_S2 } & Equal variances assumed & 0.923 & 0.357 & -3.638 & 11 & 0.004 \\
\hline & Equal variances not assumed & & & -3.498 & 7.968 & 0.008 \\
\hline \multirow[t]{2}{*}{ TEA } & Equal variances assumed & 4.085 & 0.068 & -1.487 & 11 & 0.165 \\
\hline & Equal variances not assumed & & & -1.564 & 9.012 & 0.152 \\
\hline
\end{tabular}

3.2. Attitudes and Skills Perspective skills.

This analysis involved performing the Kolmogorov-Smirnov test for the variables related to attitudes and

Table 9. Results of the Kolmogorov-Smirnov test for the analysis of attitudes and skills

\begin{tabular}{c|c|c}
\hline Variable & Statistic & Sig. \\
\hline Knoent15 & 0.148 & $0.200 d$ \\
\hline Opport15 & 0.169 & $0.200 d$ \\
\hline Suskil15 & 0.249 & 0.027 \\
\hline Frfail15 & 0.258 & 0.018 \\
\hline Nbgoodc & 0.388 & 0.084 \\
\hline Nbstatus & 0.218 & 0.023 \\
\hline Busang15 & 0.25 & 0 \\
\hline Amount & 0.361 & 0.062 \\
\hline TEA & 0.228 & \\
\hline
\end{tabular}

Regarding the results obtained from the Kolmogorov-Smirnov test (see Table 9), the variables Suskil15, Frfail15, nbgoodc, Busang15, and Amount reject hypothesis Ho (normal distribution), and therefore a different distribution from the normal distribution is followed. As per the variable of the previous perspective, the Mann-Whitney test is carried out for the cases of non-normality and the Student's t-test for the cases of normality to check whether the means of the two groups are the same.

The Mann-Whitney test is performed for the variables (Suskil15, Frfail15, nbgoodc, Busang15, Amount) to identify the differences in the central tendency of the two independent groups (the null hypothesis states that the medians of the two groups are equal). 
From the results shown in Table 10, it can be observed that the variables Suskil15, Frfail15, and nbgoodc have a higher average rank in the Southern countries with respect to the Northern countries, while the variables Busang15 and Amount, have higher average ranges in the North than in the South. However, analyzing the values of the Mann-Whitney test (see Table 11), it is concluded that the null hypothesis can be rejected only for the variable $n b g o o d c$. That is, the mean of the $n b g o o d c$ variable is significantly different between the two groups analyzed, while the variables Suskil15, Frfail15, Busang15 and Amount do not reflect significant differences in the mean values of the two groups.

\begin{tabular}{c|c|c|c|c}
\multicolumn{2}{c}{ Table 10. Results of the Mann-Whitney test for the analysis of the attitudes and skills perspective. } \\
\hline Variable & Group & $\mathbf{N}$ & Average range & Sum of ranks \\
\hline \multirow{2}{*}{ Suskil15 } & 1 & 6 & 8.50 & 51.00 \\
\cline { 2 - 5 } & 2 & 7 & 5.71 & 40.00 \\
\hline \multirow{2}{*}{ Frfail 15 } & 1 & 6 & 9.17 & 55.00 \\
\cline { 2 - 5 } & 2 & 7 & 5.14 & 36.00 \\
\hline \multirow{2}{*}{ nbgoodc } & 1 & 6 & 9.67 & 58.00 \\
\cline { 2 - 5 } & 2 & 7 & 4.71 & 33.00 \\
\hline \multirow{2}{*}{ Busang15 } & 1 & 6 & 4.83 & 29.00 \\
\cline { 2 - 5 } & 2 & 7 & 8.86 & 62.00 \\
\hline \multirow{2}{*}{ Amount } & 1 & 6 & 6.17 & 37.00 \\
\cline { 2 - 5 } & 2 & 7 & 7.71 & 54.00 \\
\hline
\end{tabular}

\section{Test Statistics ${ }^{\mathrm{a}}$}

Table 11. Test Statistics for the attitudes and skills perspective.

\begin{tabular}{l|c|c|c|c|c}
\hline & Suskil15 & Frfail15 & nbgoodc & Busang 15 & Amount \\
\hline Mann-Whitney U & 12.000 & 8.000 & 5.000 & 8.000 & 16.000 \\
\hline Wilcoxon W & 40.000 & 36.000 & 33.000 & 29.000 & 37.000 \\
\hline Z & -1.286 & -1.857 & -2.286 & -1.857 & -0.714 \\
\hline Asymp. Sig. (2-tailed) & 0.199 & 0.063 & 0.022 & 0.063 & 0.475 \\
\hline Exact Sig. [2*(1-tailed Sig.)] & $0.234^{\mathrm{b}}$ & $0.073^{\mathrm{b}}$ & $0.022^{\mathrm{b}}$ & $0.073^{\mathrm{b}}$ & $0.534^{\mathrm{b}}$ \\
\hline
\end{tabular}

Next, the Student's t-test is applied to the variables that accepted the Ho hypothesis in the normality test. In this test, the variables Knoent15, Opport15, nbstatus and TEA are analyzed.

Table 12. Variable statistics

\begin{tabular}{c|c|c|c|c|c}
\hline \multicolumn{7}{c}{ Table 12. Variable statistics. } \\
\hline Variable & Group & $\mathbf{N}$ & Mean & Std. Deviation & Std. Error Mean \\
\hline \multirow{2}{*}{ Knoent15 } & 1 & 6 & 29.852540932127200 & 4.654930238840850 & 1.900367312235320 \\
\cline { 2 - 7 } & 2 & 7 & 35.730615295752000 & 5.505027011841230 & 2.080704633432130 \\
\hline \multirow{2}{*}{ Opport15 } & 1 & 6 & 22.787560540255500 & 5.010512275664980 & 2.045533070888430 \\
\cline { 2 - 7 } & 2 & 7 & 50.691088460660900 & 14.057273114447000 & 5.313149824648750 \\
\hline nbstatus & 1 & 6 & 60.075798291152100 & 11.809326702444200 & 4.821137437802090 \\
\cline { 2 - 7 } & 2 & 7 & 62.142747429388100 & 29.082804430303600 & 10.992266850130100 \\
\hline TEA & 1 & 6 & 6.733819279855330 & 1.657850010559330 & 0.676814432656342 \\
\cline { 2 - 7 } & 2 & 7 & 8.987592508418370 & 3.365243386328870 & 1.271942443061580 \\
\hline
\end{tabular}

Table 13. Results of the Student's t-test of the analysis of attitudes and skills perspective.

\begin{tabular}{|c|c|c|c|c|c|c|}
\hline & & \multicolumn{2}{|c|}{$\begin{array}{c}\text { Levene's Test } \\
\text { for Equality } \\
\text { of Variances }\end{array}$} & \multicolumn{3}{|c|}{ T-test for average equality } \\
\hline & & $\mathbf{F}$ & Sig. & $\mathbf{t}$ & df & Sig. (2-tailed) \\
\hline \multirow[t]{2}{*}{ Knoent 15} & Equal variances assumed & 0.399 & 0.540 & -2.057 & 11 & 0.064 \\
\hline & Equal variances not assumed & & & -2.086 & 11.000 & 0.061 \\
\hline \multirow[t]{2}{*}{ Opport 15} & Equal variances assumed & 4.903 & 0.049 & -4.594 & 11 & 0.001 \\
\hline & Equal variances not assumed & & & -4.901 & 7.707 & 0.001 \\
\hline \multirow[t]{2}{*}{ nbstatus } & Equal variances assumed & 1.086 & 0.320 & -0.162 & 11 & 0.874 \\
\hline & Equal variances not assumed & & & -0.172 & 8.168 & 0.867 \\
\hline \multirow[t]{2}{*}{ TEA } & Equal variances assumed & 4.085 & 0.068 & -1.487 & 11 & 0.165 \\
\hline & Equal variances not assumed & & & -1.564 & 9.012 & 0.152 \\
\hline
\end{tabular}


From the statistical results obtained from the means of each of the variables for the groups analyzed (see Table 12), it is observed that all the variables have higher values in the North group. However, when analyzing the results of the Student's t-test (see Table 13), there are no significant differences in terms of variance for Knoent15 and nbstatus, and there are no significant differences between the values of these two variables between the countries in the North group and South group.

On the other hand, regarding the variable Opport15, it is observed that there are significant differences in terms of variance and there are significant differences between the mean values between the Northern and Southern countries.

\section{Discussion}

After analyzing the two perspectives performed in this study, that is, an evaluation of entrepreneurship in selected countries in Northern and Southern Europe from a perspective associated with national business conditions and another perspective related to attitudes and basic characteristics of the entrepreneur, some ideas can be discussed.

First, regarding the analysis of business conditions, it was identified that the variables $B 1, B 2, D 1, D 2, E$, $G 1$, and $S 1$ do not present mean values with significant differences between the two groups. These variables correspond to specific government policies, government policies and taxes, level of education in entrepreneurship at the basic primary and secondary education level and at the university and professional level, level of transfer in R\&D, dynamism of the internal market, and the consideration of businesses as providers of basic social needs.

There is a strong link between government programs and education regarding the actions taken in entrepreneurship (Acs, Åstebro, Audretsch, \& Robinson, 2016) since they have a multiplier effect and lead to the identification of business opportunities that can subsequently result in entrepreneurial activity. The level of transfer in R\&D is also positively related to entrepreneurship (Díaz-Casero, Hernández Mogollón, SánchezEscobedo, \& Postigo Jiménez, 2012) since it facilitates entrepreneurship, especially related to technology and innovation.

Likewise, the variable directly related to entrepreneurship (TEA) measures the percentage of the population of working age, that is, in the age range 18-64 years, who are about to start a business or who have started a business in the last three and a half years, according to the definition of the GEM database (GEM, 2016). There are significant differences between the most extreme values of the group. The highest value corresponds to Latvia (Northern group), with a $T E A$ value of $14.1 \%$, while the lowest value belongs to Italy (Southern group) with a value of $4.86 \%$. It is also important to analyze the highest value of the Southern group and the lowest value of the Northern group. In the Southern group, the highest value belongs to Portugal, with a value of $9.48 \%$, and in the North group the lowest value corresponds to Norway with a value of $5.65 \%$. Surprisingly, the results obtained reflect that the mean values between the two groups do not present significant differences. For variables $A, F, G 2, H, I$, and $S 2$, which correspond to the financial environment associated with entrepreneurship $(A)$, access to professional and commercial infrastructure $(F)$, barriers in the market internal $(G 2)$, access to physical infrastructure $(H)$, support of the social and cultural environment for entrepreneurship $(I)$ and the demand for social responsibility of entrepreneurs by social agents $(S 2)$, differences were identified between the means of the countries associated with the Northern group and the countries associated with the Southern group. In all of them, the values are higher in the Northern group. It is known that the availability of financial support is a key factor in entrepreneurship (Anton \& Onofrei, 2016). On the other hand, market barriers and access to physical infrastructure are two of the main factors that can respectively obstruct and enhance the transformation of new business opportunities for companies (Holienka, Pilkova, \& Ostapenko, 2016). According to Curran, Lynn, \& O'Gorman (2016), access to professional and commercial infrastructure plays an important role in creating new business opportunities, both at the business support level and at the entrepreneurial motivation level. Second, with respect to attitudes and basic characteristics, the variables Suskil15, Frfail15, Busang15, Amount, Knoent15 and nbstatus do not present mean values with significant differences between the two groups. These variables correspond to having the knowledge and skills necessary to start a business (Suskil15), being afraid of failure (Frfail15), getting involved in entrepreneurial activities as an informal investor (Busang15), the total money needed to start a business (Amount), personally knowing someone who started a business in the last two years (Knoent15), and the success associated with starting a business with a high level of status and respect (nbstatus). The variable that presents significant differences when analyzing the means between the two groups is Opport15, which is directly associated with perceiving good opportunities to start a business in the entrepreneur's area of residence, where the mean value of the Southern countries is 22.78 while in the Northern countries it is more than double that value, at 50.69. Therefore, the main difference found with respect to this perspective is related to the perception of the opportunity to invest in a startup.

\section{Conclusions}

In this analysis, it is certified that in terms of entrepreneurship, there are differences in European countries, specifically between the countries of Northern and Southern Europe. Entrepreneurship is strongly 
related to economic growth, job creation, and innovation, and it is important to analyze and investigate the differences between the different zones or areas to identify potential factors that can promote the growth of entrepreneurship.

The results obtained in this analysis show differences between the Northern and Southern countries for the two analysis perspectives used.

From the analysis of business conditions, the main differences between the group of Northern European countries and the group of Southern countries are related to the financial environment, access to professional and commercial infrastructure, barriers in the domestic market, access to physical infrastructure, social and cultural support for entrepreneurship as well as the level of demand for social responsibility of entrepreneurs. This shows that, despite the fact that the barriers in the internal market are higher in the countries of the North compared to those of the South, they also present notable advantages by having a better financial environment, better access to professional and commercial infrastructure, and physical as well as stronger support from society towards entrepreneurship.

Regarding the analysis of attitudes and basic characteristics, it is striking that, of the variables studied, the only one that has significant differences in terms of the average level of the two groups is the one associated with perceiving good opportunities to start a business in the area of residence.

Based on these conclusions, Southern countries could implement programs that improve access to finance for entrepreneurs in certain sectors, improve access to physical, professional and commercial infrastructure, and facilitate entrepreneurial promotion campaigns through different formats.

On the other hand, the perception of opportunities is closely related to education, but also to the situation of the labor market and access to financing to realize those ideas. Improving the education associated with entrepreneurship (through knowledge, skills and experience), improving labor market conditions and facilitating access to financing could help potential entrepreneurs to identify a greater number of business opportunities.

This analysis complements the existing analyses on entrepreneurship, with the analysis of the characterization of entrepreneurship in the North and South of the European continent being especially interesting. It is important to consider the limitations of this study since the analysis was carried out in 2015 and only for countries with available data from Northern and Southern Europe. This type of analysis could be extended to compare other regions and include additional data with more recent information.

References

Acs, Z., Åstebro, T., Audretsch, D., \& Robinson, D. T. (2016). Public policy to promote entrepreneurship: A call to arms. Small Business Economics, 47(1), 35-51. Available at: https://doi.org/10.1007/s11187-016-9712-2.

Anton, S. G., \& Onofrei, M. (2016). Public policies to support entrepreneurship and SMEs. Empirical evidences from Romania. Transylvanian Review of Administrative Sciences, 12(47), 5-19.

Beynon, M. J., Jones, P., \& Pickernell, D. (2016). Country-based comparison analysis using fsQCA investigating entrepreneurial attitudes and activity. Journal of Business Research, 69(4), 1271-1276. Available at: https://doi.org/10.1016/j.jbusres.2015.10.091.

Breschi, S., Lassébie, J., \& Menon, C. (2018). A portrait of innovative start-ups across countries. OECD Science, Technology and Industry Working Papers, No. 2018/02, OECD Publishing, Paris.

Curran, D., Lynn, T., \& O'Gorman, C. (2016). The role of personal factors in the location decision of software services start-up firms. European Planning Studies, 24(3), 551-567. Available at: https://doi.org/10.1080/09654313.2015.1046369.

Díaz-Casero, Hernández Mogollón, R., Sánchez-Escobedo, M. C., \& Postigo Jiménez, M. V. (2012). Entrepreneurial activity and gender. A comparative study. European Journal of Business Management and Economics, 19(2), 83-98.

Eurostat. (2018). Business demography statistics. Retrieved from https://ec.europa.eu/eurostat/statisticsexplained/index.php?title=Business_demography_statistics.

GEM. (2016). Global entrepreneurship monitor for 2016/2017. Retrieved from https://www.gemconsortium.org/report/gem-2016-2017-global-report.

Holienka, M., Pilkova, A., \& Ostapenko, N. (2016). Entrepreneurial environment and economic growth: What affects the productiveness of business activity at macro level? In: The Essence and Measurement of Organizational Efficiency (pp. 79-95): Springer Proceedings in Business and Economics.

Khyareh, M. M., \& Torabi, H. (2018). Investigating the role of entrepreneurship ecosystem in Iran's economic growth. The IUP Journal of Entrepreneurship Development, 15(4), 7-25.

Klimis, V. (2019). Do entrepreneurial attitudes explain the rising international business orientation in developing and emerging economies? Studies in Business and Economics, 14(2), 245-256. Available at: https://doi.org/10.2478/sbe-2019-0038.

Lopes, J., Rodrigues, R., \& Antunes, H. (2018). Comparative entrepreneurship between Western Europe and Latin America. Entrepreneurship Research Journal, 8(4), 1-20. Available at: https://doi.org/10.1515/erj-2017-0058.

World Economic Forum. (2017). Europe's most entrepreneurial country? It's not the one you might expect. Retrieved from https://www.weforum.org/agenda/2017/03/europes-most-entrepreneurial-country/. 